\title{
NACER ES UN RITUAL: COMPADRAZGO, CUVADA Y PADRINAZGO INDIGENA
}

Alonso Zarzar

"Sobre la bumillación comuin de las madres se construyen los variados simbolos del poder"

M. Bloch y S. Guggenheim

The aim of this article is to discuss the major explanations given thus far for variations of the compadrazgo complex and to propose a more meaninful approach to the institution, by taking into account other similar ritual practices beyond the influence of Christianity, such as couvade, and a case in which birth itself comprises ritual ceremonies.

* $* 4$

Le but de cet article est d'aborder les principales explications concernant les variations du "compadrazgo". De plus il propose une approche plus intégrale de cette institution, considérant des pratiques rituelles similaires, au delà de l'influence du christianisme. C'ést le cas par exemple lorsque la naissance même implique une cérémonie rituelle.

* $4 *$

In der Arbeit werden die Haupterklärungen für die Variationen bei der (compadrazgo) diskutiert. Eine integrale Annäherung an diese Institution wird vorgeschlagen, durch eine Einbeziehung anderer äbnlicher ritueller Praktiken jenseits christlicher Einflïsse. Als Beispiele dafür werden das Männerkindbett angeführt und ein Fall, in dem die Geburt selbst rituelle Praktiken beinhaltet. 


\section{INTRODUCCION}

La importancia social de la institución del compadrazgo, tanto en los paises mediterráneos como en América Latina ha sido largamente explorada debido fundamentalmente a que 'su rol cultural se afirma mas allá del padrinazgo por el bautismo' (Mintz y Wolf 1968: 328). Hay una razón histórica obvia que explica la amplia presencia del compadrazgo en América Latina: el bautismo fue usado por los españoles como uno de los medios más importantes en la conquista y colonización, tanto en un sentido espiritual como material. Nutini y Belt (1980) han listado 250 fuentes etnográficas sobre este tema, sólo para América Latina. En estos estudios así como en trabajos teóricos, la amplitud en las variaciones del compadrazgo ha sido uno de los temas más importantes y complejos. Mientras que la definición y comprensión específicas de esta institución en diversos contextos sociales, han sido extensamente elaborados, el hecho de la variación continúa siendo un centro polémico en la literatura.

El objetivo de este artículo es discutir las explicaciones más importantes respecto a las variaciones del complejo del compadrazgo y proponer un acercamiento más significativo, mediante la incorporación en el análisis de prácticas rituales semejantes, más allá de la influencia del cristianismo, como es el caso de la cuvada y un caso en el cual el nacimiento mismo conlleva ceremonias rituales. El punto de partida teórico es aquel formulado por Riviere (1974: 427) para el estudio de la cuvada, el tratamiento de estos fenómenos no como objetos de estudio aislados sino como formas específicas de un fenómeno mayor.

El artículo se divide en cuatro partes. En la primera se intenta una definición operacional del compadrazgo. La segunda desarrolla una discusión sobre las explicaciones dadas para entender la variedad de formas que esta institución ha adquirido. La tercera parte consiste en una comparación de las similitudes simbólicas y sociológicas del compadrazgo y la cuvada. En la última sección se intenta una explicación preliminar de un caso de 'compadrazgo múltiple' entre los Piro, grupo étnico que habita el Bajo Urubamba en la Amazonía Peruana.

\section{EL COMPLEJO DEL COMPADRAZGO}

La institución del compadrazgo ha sido vista usualmente como compuesta por dos aspectos interrelacionados:

a) una base simbólica inscrita en el ritual cristiano del bautismo que implica una distinción entre el parentesco natural y el parentesco espiritual y b) una base sociológica específica para el establecimiento de una red de relaciones sociales (Bloch y Guggenheim 1980: 376). Estos dos aspectos han dado lugar a dos tipos de aproximación. Mientras que la mayoría de estudios se han concentrado en el análisis \de los aspectos sociales y funcionales de la institución, sólo en los últimos quince años algunos estudios han apuntado al trasfondo ideológico.

Hasta cierto punto puede decirse que la institución del compadrazgo ha sido entendida de tantas maneras como aspectos tiene. Así ha sido aproximada como una forma de co-paternidad (Goody, E.N, 1977) en la que el compadrazgo es una manera, entre otras, de compartir los roles en la relación entre padres e hijos. En el compadrazgo, es el rol del padrino/madrina - caracterizado por la mediación que 
establece entre el niño y el sistema externo el que es compartido con los padres naturales. En un trabajo más reciente (Goody, E.N. 1982: 27) este autor enfatiza, al igual que Mintz y Wolf (1968: 343), que en el contexto de América Latina, el vínculo con los padres naturales es aquél sobre el que recae la importancia funcional de la institución. Mientras que en teoría el rol del padrino/madrina es el centro de las ceremonias, en la práctica la relación entre los compadres es la predominante (Nutini y Belt 1980: 424).

Mintz y Wolf (ibid: 327) y Pitt-Rivers (1968) ponen el énfasis en la naturaleza ritual de los vínculos por compadrazgo. Pitt-Rivers considera que el compadrazgo es como la hermandad de sangre, un sistema que establece vínculos análogos a los lazos de parentesco. El compadrazgo designa un complejo específico de relaciones establecidas principalmente, pero no siempre, por la participación en el ritual católico del bautismo. Su estructura básica consiste en tres relaciones:

1. Un vínculo de parentesco entre padres e hijos.

2. Un lazo espiritual entre los padrinos y el niño/a.

3. Un lazo espiritual entre los padrinos y los padres.

Las dos últimas están a su vez relacionadas al sistema de parentesco así como a las condiciones económicas de una organización social dada; puntos que serán desarrollados más adelante.

Vínculo de parentesco

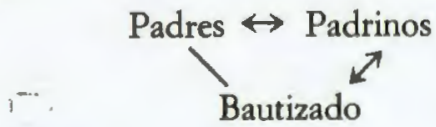

Relación espiritual $\leftrightarrow$

Gráfico 1: El conjunto del compadrazgo

(Fuente: Gudeman 1972)

El hecho que el ritual del bautismo sea considerado en la teología católica y cristiana como una forma de re-nacimiento espiritual, es el punto de partida que toma Gudeman (1972: 47) para afirmar que el conjunto de relaciones de compadrazgo media entre el nacimiento y el bautizo, puesto que se basa en un compartir al bautizado. Así, el compadrazgo comparte las características fundamentales de esos conjuntos opuestos: las relaciones naturales y biológicas entre padres e hijos y las relaciones espirituales, rituales, sagradas, sociales y afines que conlleva el bautismo.

\section{Conjunto del compadrazgo}

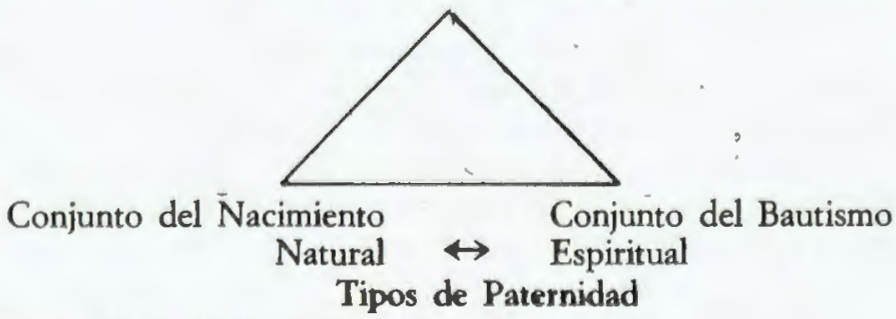

Gráfico 2: Interrelación de los conjuntos del

nacimiento, el bautismo y el

compadrazgo.

(Fuente: Gudeman 1972) 
Pero Gudeman vá más allá en su énfasis sobre el contenido ideológico de la institución. Para él, éste se basa en la concepción de la naturaleza dual del hombre en tanto que ser natural y espiritual.

A pesar que tanto Mintz y Wolf, como Pitt-Rivers, notaron que el compadrazgo, representa una sintesis de ideas acerca del padrinazgo, y del parentesco ritual y espiritual, ellos enfatizaron este último aspecto. Pero las contradicciones en estas definiciones son mínimas. Todos comparten la idea que el compadrazgo se encuentra inmerso en la práctica ritual cristiana de un segundo nacimiento. Sin embargo, desde el análisis seminal de Gudeman, se han realizado nuevos intentos por colocar al compadrazgo en una perspectiva más amplia. Mediante una torsión de la idea central de Gudeman y tomando en cuenta algunas afirmaciones embriónicas de otros autores - principalmente Pitt-Rivers (1977) y Ortner (1974) — Bloch y Guggenheim (1980) han intentado un acercamiento cross-cultural al compadrazgo, mientras Riviere (1974) ha analizado la cuvada.

Aunque Gudeman no niega la universalidad de la concepción de la naturaleza dual del hombre, considera que es específicamente cristiano depositar estos aspectos opuestos en conjuntos separados de padres: el aspecto natural en los padres biológicos y el aspecto espiritual en los padres apadrinadores (ibid: 47). Como veremos, esta división no es exclusiva del cristianismo ya que se encuentra por ejemplo en ceremonias rituales en la Amazonía.

\section{LA NOCION DE VARIACION Y SUS EXPLICACIONES}

Los antropólogos que han tratado el tema del compadrazgo en forma comparativa consideran que éste tiene numerosas expresiones en América Latina. Esto se manifiesta en las repetidas afirmaciones sobre su carácter flexible y su capacidad de adaptación (p.e. Mintz y Wolf 1968: 334). Tales ideas sobre la variación pueden ser muy limitadas, pues se encuentran encerradas en las relaciones entre los aspectos funcionales de la institución y los diversos contextos sociales. Cuando Mintz y Wolf se preguntan acerca de las razones que explicarían el éxito del compadrazgo entre las poblaciones indígenas, en vez de analizarlo en términos comparativos, cancelan toda respuesta adecuada con la simple afirmación que tal éxito se debió a la simplicidad simbólica del compadrazgo, que lo hizo fácilmente aceptable para esas poblaciones (ibid: 341). Ellos se oponen a la idea de la existencia de patrones indígenas preexistentes con los cuales el nuevo complejo pudo integrarse.

Este último intento de explicación fue realizado por Paul (1942) y Foster (1953), quienes implícitamente trataron el problema de la variación. De acuerdo con ellos, una de las probables razones para la aceptación del compadrazgo en América Latina fue su similitud con formas nativas, tales como el padrinazgo ceremonial, la 
amistad ritualizada y sobre todo, los sistemas de parentesco nativos desbaratados por el contacto con los españoles (Foster 1953: 23). Foster parte del hecho que antes de la conquista, las sociedades indigenas se caracterizaban por tener un sistema de clanes, linajes y familias extensas más amplio y desarrollado que hoy en dia. Pero, aún en la actualidad encontró que, al menos en Chiapas (México), el sistema de clanes tiene, entre otras funciones, el proveer de nombres al individuo, llenando así una de las funciones que posteriormente o en otras regiones cumple el bautismo. Más significativo aún es que el compadrazgo no logró ser firmemente establecido en esta región. Para él, como para Mintz y Wolf, el compadrazgo tuvo éxito sólo ahí donde tenía algo útil que ofrecer: principalmente medios de solidaridad social. Con un ejemplo contrastante tomado de México Central, Foster ilustra esta idea. Ahí, la estructura de clanes precolombina casi ha desaparecido y en su lugar existe un amplio sistema de padrinazgo. Como Paul, él alude a la creciente importancia del compadrazgo como concomitante de la decreciente importancia del parentesco; correlación negativa que también es claramente visible en pueblos de 'frontera' como Sepahua en la Amazonía Peruana, donde el cambio social ha afectado el sistema de parentesco de las poblaciones nativas. Este punto fue formulado por Mintz y Wolf (1968: 341) en términos de la relación entre la utilidad de los lazos de compadrazgo y el impacto del cambio social. Según estos autores, en una situación de transición -donde las relaciones impersonales o de mercado empiezan a reemplazar los vínculos de parentesco, pero sin llegar a desarrollarse plenamente- el compadrazgo es una suerte de estrategia desesperada que apunta a copar con tal campo. Razón por la cual se encuentra en comunidades que están entre un sistema social basado en el parentesco y un sistema social regulado por relaciones de mercado.

En breve, Foster ha señalado tres razones que darían cuenta del éxito del compadrazgo:

1. La necesidad funcional de las sociedades indígenas y de los mestizos emergentes por ayuda mutua y medios de integración.

2. La flexibilidad y el potencial de crecimiento del compadrazgo que le permite suplir esas necesidades.

3. La similitud entre algunos de sus ritos y formas y los ritos y formas indigenas que lo hicieron atractivo a las poblaciones nativas.

Mientras que las dos primeras razones están relacionadas con los aspectos funcionales del compadrazgo - en tanto institución de clientelaje y en tanto que medio de solidaridad social - la tercera razón puede considerarse como un paso hacia una comprensión cross-cultural de la institución y por lo tanto como uno de los primeros intentos de asir el problema de la variación. Sin embargo este es todavía un paso limitado, inserto en una aproximación funcional basada en la idea de un sincretismo que cancela una visión estructural de las similitudes fundamentales y los fundamentos simbólicos del compadrazgo y de las prácticas rituales no cristianas. En vez de concebir esas otras instituciones como ceremonias rituales paralelas al complejo del compadrazgo, la relación con el compadrazgo es entendida como una expresión de la adaptabilidad de la institución. Pero aún la adaptabilidad del compadrazgo permanece irresuelta. De acuerdo con Gudeman (1972: 46), Foster y Paul no pueden decir por qué es el compadrazgo y no otra institución la que cubre el vacío dejado por los lazos de parentesco. La respuesta yace en la naturaleza de la relación entre la estruc- 
tura del compadrazgo y los vínculos parentales. En su forma básica, el conjunto de relaciones formado por el compadrazgo es un simulacro de las relaciones familiares básicas; tema sobre el cual volveremos posteriormente.

De todos estos acercamientos, aquél desarrollado por Gudeman es el que está más sistemáticamente relacionado con el problema de la variación. Sin embargo, su perspectiva se encuentra encerrada en lo que él llama la 'estructura invariante' del conjunto del compadrazgo, que para él constituye el límite de las variaciones y por lo tanto el límite para establecer comparaciones. Gudeman se refiere a las variaciones, frecuentemente dramáticas, como modificaciones inherentes a los lazos establecidos. Estas incluyen:

1. Incrementar el número de ocasiones para establecer lazos. El conjunto de relaciones puede ser repetido o extendido de los rituales eclesiásticos a otros ritos como p.e. el primer corte de pelo o el caso del 'susto' como ocurre en las comunidades andinas.

2. Aumentar el número de padrinos sin incrementar el número de ritos. El efecto sin embargo es el mismo que en 1.

3. Expandir los lazos espirituales a los parientes de los miembros principales del conjunto del compadrazgo. Los abuelos del bautizado pueden devenir compadres de los padrinos; los parientes de los padrinos pueden ser involucrados, como ocurre cuando los hijos de los padrinos se relacionan con el bautizado como 'hermanos políticos ${ }^{1}$. Pero como dice Gudeman (1972: 63), es importante no identificar las extensiones de los términos con las extensiones de las relaciones. Así, a un individuo categorizado como compadre - sin ser realmente un padrino- no le afectan los derechos y deberes del vínculo. Esta extensión terminológica es común en los contextos urbanos peruanos donde los términos 'compadre' y 'cuñado' son usados principalmente por los hombres para expresar confianza, amistad y confidencia pero sin existir lazo espiritual alguno. Parece ser que hay una correlación inversa entre la importancia social de la institución -menos importante en los centros urbanos que en los rurales - y la extensión en el uso de los términos - menos restrictivo en los centros urbanos que en los rurales.

4. La posición del bautizado puede ser repetida. Esto puede ocurrir cuando hay una proliferación de niños y/o ceremonias para el mismo padrino o cuando una sola persona apadrina a un grupo de hermanos. Diríamos que esta variante tiene como efecto principal el incremento del prestigio del individuo apadrinador.

5. La prohibición de revertir la elección del padrino es quizás la regla más difícil de explicar ya que sintetiza casi todos los aspectos del compadrazgo. De acuerdo con Gudeman esta prohibición es casi universal, sin embargo hay una variedad de casos en los cuales la reversión de los roles de los padrinos y de los padres no solamente no se prohibe pero incluso se prescribe. Esto ocurre no sólo en el caso del compadrazgo húngaro que Gudeman describe. Entre las clases medias urbanas del Perú es una costumbre devolver el privilegio - y no sólo la deuda como piensa Gudemande ser seleccionado padrino mediante la selección de un compadre como padrino. En este contexto la elección recíproca tiene lugar entre miembros de la misma clase social que la mayoría de veces son además parientes consanguineos o afines.

1 Término usado en América Latina para referirse también al cuñado, cuestión que ilustra la semejanza entre los lazos por compadrazgo y los vínculos de afinidad. 
Gudeman ha explicado de diversas maneras la supuesta universalidad de la prohibición de la elección recíproca. Primero consideró que esta prohibición era esencialmente una 'deducción folk de la teología eclesiástica' en la cual las relaciones espirituales ocupan un estatus más alto que las relaciones naturales, principio que coloca a los padrinos en una posición más elevada que la de los padres. Si la elección fuera recíproca, cada uno (padre y padrino) sería compadre para el otro y se establecerían relaciones naturales y espirituales y cada uno ocuparía ambos estatus. Gudeman concluye: "Mediante la prohibición de la elección recíproca se evita una situación estructuralmente imposible" (1972:63). Uno puede preguntarse, ¿imposible, para quién, para el antropólogo ansioso por construir un modelo, o para los propios actores sociales?

En un artículo posterior (1975: 233) Gudeman argumenta sobre bases sociológicas antes que simbólicas. En contextos de sistemas de parentesco bilateral como en Veraguas (Panamá) él encontró que los grupos sociales discretos y contiguos se forman en base a relaciones políticas y de localidad antes que sobre principios de parentesco. Gudeman sostiene que si la fórmula recíproca funcionara, esta tendría que establecerse entre pares de cónyuges, en una suerte de intercambio binario que impediría una relación estructural de continuidad entre los grupos generacionales. Esta explicación funcional se basa sin embargo en un supuesto, más bien dudoso: que un sistema indirecto de alianzas de compadrazgo introduce elementos de "mayor cohesión social ${ }^{12}$ en lo que sería de otro modo una sociedad estructurada de manera fluida o fragmentada. Chevalier (1982: 330) ha encontrado una situación contrastante en Puerto Inca - un asentamiento mestizo en la Amazonía Peruana - basado también en un sistema de parentesco bilateral. De acuerdo con Chevalier ahí el compadrazgo encaja no con las demandas de un sistema amorfo de relaciones sociales, sino más bien con la atenuación de las tensiones que surgen de un rígido estructuramiento de relaciones económicas que el sistema cognático y la solidaridad de la familia nuclear son incapaces de resolver por sí solos. Idea que fue previamente adelantada por Pitt-Rivers (1968: 412): “...el compadrazgo es lo que el parentesco cognático aspira a ser, pero no puede ser". Este contraste entre lazos de parentesco ritual y vínculos de parentesco se expresa mejor en la función económica que llevan a cabo los primeros y que implica una redistribución de la riqueza. Así, el complejo del compadrazgo tiene éxito en realizar lo que ni la solidaridad consanguínea, ni la solidaridad por afinidad pueden alcanzar: permitirle a un individuo elegir entre aquellos de quienes puede esperar apoyo económico como si se tratase de parientes cercanos. Es precisamente este análisis que incorpora las condiciones económicas el que está ausente en la explicación sociológica de Gudeman. Siguiendo a Chevalier puede decirse que las deudas canceladas por la elección recíproca (de acuerdo con Gudeman) no constituyen un sistema de intercambio indirecto sino una combinación de dos conjuntos opuestos de intercambios asimétricos. Es un intercambio entre el que posee bienes materiales y busca un prestigio consagrado espiritualmente y el desposeído que 'renuncia' a los bienes materiales y que es obligado a buscar el apoyo material de individuos más poderosos. Revertir la elección es por lo tanto devolver dos deudas: el mayor prestigio asignado al padrino y la asistencia caritativa que este 'debe' a sus parientes rituales dependientes. Este aspecto está ausente en el análisis de Gude-

2 Cuestión que el mismo Gudeman ha criticado en la aproximación de Mintz y Wolf (1972: 45-46). 
man porque él asume que un compadre debe ser el 'dador' y el otro el 'recibidor', pero ambiguamente añade que el padrino ocupa el estatus más alto, sea este el dador o el recibidor (1975: 234). Pero, ¿cómo puede un padrino no ser definido como 'recibidor', al menos en el sentido de ser alguien que obtiene mayor prestigio? (Chevalier 1982: 331).

Hasta donde podemos entender este problema parece ser que la modalidad de la elección recíproca se prohibe en aquellas sociedades donde el compadrazgo juega un rol crucial en las relaciones socio-económicas. Podemos afirmar que en las zonas urbanas, gruesamente caracterizadas por la existencia de medios alternativos para la movilidad social y la solidaridad social, donde la familia es básicamente una unidad de consumo y donde la esfera doméstica de actividades depende ampliamente de las condiciones económicas y políticas societales, el compadrazgo no es solamente menos importante, sino que la elección recíproca no se prohibe. Por otro lado, en las comunidades campesinas y las sociedades 'tribales' el compadrazgo no solamente es importante como medio funcional múltiple, sino que la elección recíproca es prohibida.

Regresando a Gudeman revisemos su argumento subyacente para explicar el hecho de la variación. De acuerdo con él, detrás de los diferentes patrones y normas yace la estructura invariable del conjunto del compadrazgo y su relación con la familia. Hay dos puntos aquí que merecen comentarse. En primer lugar, cuando el conjunto del compadrazgo es abordado dentro de una dimensión cross-cultural puede ser visto como una institución entre otras instituciones y prácticas de apadrinamiento que no están ligadas a la tradición cristiana.

En segundo lugar, la estructura de la familia, que el compadrazgo aparenta simular, es una organización en sí misma cambiante. Así, el argumento de Gudeman parece asentarse en una fundamentación incierta, en la que ambos objetos correlativos son en sí mismos cambiantes. Diríamos que esta limitación es el resultado de intentar explicar el hecho de la variación al nivel de la institución misma. Para Gudeman todas las variaciones del compadrazgo han derivado de la misma 'gran tradición' y están ligadas por su conexión histórica a la difusión del cristianismo. Mediante el establecimiento de una división entre aquellas instituciones que emergieron de la gran tradición y aquellas que pertenecen a otras tradiciones (cuvada, rituales de nombramiento, ritos de nacimiento, etc) él cancela una aproximación cross-cultural y omite la comparación más allá de esos límites. En este sentido su visión se opone a los intentos comparativos de Eisenstadt (1956) y Pitt-Rivers. Pese a que estos autores comparten la idea que el compadrazgo se basa en la ideología cristiana, consideran que esta institución era comparable a la amistad formalizada y a los lazos estableci. dos por las hermandades de sangre.

Para Gudeman, el compadrazgo es una institución cristiana única porque es la única que deposita la dicotomía natural/espiritual en dos conjuntos diferentes de padres. Como veremos luego, esta supuesta característica distintiva es compartida por otros rituales no cristianos y ceremonias de apadrinamiento en algunas sociedades amazónicas. Sin embargo, esta distinción específica no se encuentra en el caso de la cuvada, en la que los mismos padres naturales juegan también el rol de creadores del lado espiritual del niño (Riviere 1974). En cambio, lo natural y lo espiritual se divide entre los padres naturales; la madre produce el nacimiento biológico, el padre, el nacimiento espiritual, una dicotomía simbólica de los géneros que de acuerdo con Bloch y Guggenheim también es fundamental al compadrazgo. Así, de una forma u 
otra, ya sea por entregar la dicotomía natural/espiritual a conjuntos diferentes de padres (rituales de nombramiento) ${ }^{3}$ o por la atribución de cada lado de la dicotomía a cada género (cuvada), el simbolismo del compadrazgo es una base para la comparación cross-cultural. En todos estos casos estamos confrontados con un segundo nacimiento, un nacimiento espiritual y social que se sostiene en oposición al nacimiento natural y biológico.

Gudeman no ha explorado este aspecto porque él está interesado únicamente en las diversas variaciones de una misma estructura y en una explicación situacional (1972: 48) que es importante sólo como una base para la comparación al interior de formas de compadrazgo cristianas o influenciadas por el cristianismo, pero no está interesado en el hecho de la variación en sí. Para poder explicar el problema de la variación se tiene que cambiar el centro del análisis y se tienen que ver las otras instituciones como manifestaciones ligadas al compadrazgo, no solamente porque estas se dirigen al mismo problema (Riviere 1974), sino porque las soluciones mismas son sorprendentemente semejantes.

Esta última posición fue desarrollada por Bloch y Guggenheim (1980) y Riviere quienes empezaron con el análisis del simbolismo del compadrazgo en diferentes contextos culturales. Bloch y Guggenheim intentan explicar porque el mismo complejo ritual de un segundo nacimiento ha sido utilizado en instancias históricas diferentes y especificas; hecho que les hace preguntarse "...si es que hay algo intrínsico a la institución que la hace tan dócil a los préstamos y transformaciones que ha sufrido..." (1980: 377). Para ellos los cimientos básicos del compadrazgo yacen en el simbolismo de los géneros, el nacimiento y la paternidad penetrados por el contraste entre el parentesco natural y espiritual. El bautismo es un segundo nacimiento espiritual y superior, sagrado y puro porque se asemeja al nacimiento divino de Cristo, ${ }^{4}$ de manera opuesta al nacimiento natural que es profano y 'sucio'. El bautismo es un exorcismo de esta contaminación que involucra una devaluación de la naturaleza, del nacimiento y de las mujeres en tanto que dadoras de vida. Aún más, la fuente bautis$\mathrm{mal}$ es una vagina superior que incorpora a los niños en la comunidad moral. El bautismo es un ritual que afírma que las mujeres no pueden producir niños socialmente aceptables y enviste la creación de seres humanos completos ya sea en Dios o en la Iglesia (ibid: 379-80). A través del tiempo el rol del padrino, en las relaciones creadas por el bautismo, se ha incrementado a costa del rol de la Iglesia. En todo América Latina, el término 'político', que es usado para expresar varias relaciones de afinidad como relaciones a través de padrinos, también expresa la idea que todos estos lazos son creaciones de la comunidad, donde esta aparece en su representación más sagrada. De acuerdo con Gudeman, en Veraguas el contraste entre lo natural y lo espiritual va unido al contraste entre la casa familiar y la comunidad; los padres

3 Para el análisis de los rituales de nombramiento, véase por ejemplo Maybury.Lewis, D. (ed.), Dialectical Societies, The Ge and Bororo of Central Brazil, 1979. (1969).

4 Para una provocativa discusión sobre el nacimiento virginal de Cristo, véase el artículo de Leach

5 Pese a que esta es una ideologia especifica con la que debemos ser cuidadosos en no proyectarla en la explicación de otros ritos no cristianos, existen otras dicotomías homólogas entre las sociedades amazónicas, como las oposiciones entre las esferas de relaciones públicas y privadas o entre las actividades rituales y seculares que hacen del compadrazgo una práctica manifiestamente comparable con otros rituales. 
naturales están asociados a la casa mientras que los padres espirituales están asociados con la comunidad. De esa manera podemos apreciar que los lazos establecidos por el compadrazgo son el resultado de una intervención 'creativa' de la autoridad político-religiosa de la cual los padrinos son meros intermediarios y representantes. Esto sugiere también una oposición simbólica de los géneros ya que la casa está simbólicamente asociada a las mujeres. La comunidad consiste de ambos sexos, pero está representada y dominada por los hombres (Bloch y Guggenheim 1980: 380). Así, nacer a través del bautismo, que es nacer por segunda vez, es también nacer por los hombres. La pregunta obvia es entonces, por qué los hombres necesitan 'dar a luz'. La respuesta tiene que ver con la necesidad de tener medios de dominación, medios para legitimar la autoridad y canales para el mantenimiento de la reproducción social y la continuidad ideológica de la sociedad. Mediante la realización de un segundo nacimiento conducido por los hombres, la esfera femenina de relaciones domésticas es invadida y puesta bajo el control de la esfera masculina de relaciones juridicas y públicas. Mediante la repetición del nacimiento natural, la reproducción biológica de la sociedad es transformada en la reproducción social bajo el control de los hombres. De ese modo, el compadrazgo es el complejo simbólico y sociológico mediante el cual el individuo nace dentro de y para la comunidad. En este sentido el compadrazgo es un ritual de pasaje, pues marca el paso del individuo, de la esfera

Cuadro 1

\begin{tabular}{|c|c|c|c|}
\hline \multirow{2}{*}{$\begin{array}{l}\text { NOCIONES DE } \\
\text { VARIACION }\end{array}$} & \multicolumn{3}{|c|}{ VISIONES DEL COMPADRAZGO } \\
\hline & $\begin{array}{l}\text { Una sola estructura } \\
\text { basada en la dicoto- } \\
\text { mía cristiana del ser } \\
\text { natural y espiritual. }\end{array}$ & $\begin{array}{l}\text { Un complejo sincré- } \\
\text { tico de nociones } \\
\text { cristianas y rituales } \\
\text { indigenas (en A. La- } \\
\text { tina) }\end{array}$ & $\begin{array}{l}\text { Un segundo naci- } \\
\text { miento, un naci- } \\
\text { miento social y ri- } \\
\text { tual que asegura y } \\
\text { legitima la domina- } \\
\text { ción de clase y/o gé- } \\
\text { nero (entre otras } \\
\text { instituciones no cris- } \\
\text { tianas). }\end{array}$ \\
\hline $\begin{array}{l}\text { Una expresión de la } \\
\text { flexibilidad y adap- } \\
\text { tabilidad del compa- } \\
\text { drazgo. }\end{array}$ & Mintz y Wolf (1968) & $\begin{array}{l}\text { Foster (1953) } \\
\text { Paul (1942) } \\
\text { Redfield y Villa } \\
\text { Rojas (1962) }\end{array}$ & \\
\hline $\begin{array}{l}\text { Una repetición múl- } \\
\text { tiple de una sola es- } \\
\text { tructura. }\end{array}$ & $\begin{array}{l}\text { Gudeman } \\
1975)\end{array}$ & & \\
\hline $\begin{array}{l}\text { El resultado del uso } \\
\text { de este complejo } \\
\text { simbólico en dife- } \\
\text { rentes contextos } \\
\text { socio-politicos. }\end{array}$ & $\begin{array}{l}\text { Mintz y Wolf (1968) } \\
\text { Gudeman } \\
\text { 1975) } \\
\text { Pitt-Rivers } \\
\text { 77) }\end{array}$ & & $\begin{array}{l}\text { Bloch y Guggen- } \\
\text { heim (1980) } \\
\text { Riviere (1974) }\end{array}$ \\
\hline
\end{tabular}


Ilsméstica y privada a la esfera pública y jurídica de la sociedad. Es este complejo Unhbólico subyacente de nociones y relaciones el que encontraremos aún de manera mis marcadamente expresado en otras prácticas de segundos nacimientos en algunas nocjedades amazónicas.

Bloch y Guggenheim han demostrado la posibilidad de un análisis comparativo iruss-cultural con ejemplos de segundos nacimientos tomados de los Merina de Madagascar, los Esquimales y la sierra de México en el periodo previo a la conquista. Bllos encontraron que casi todas las características del compadrazgo estaban presenics, pero que los padres sustitutos o padrinos variaban en extremo. Entre los Merina, los padrinos son un hombre y un grupo de mujeres vírgenes; entre los Esquimales y lon Aztecas es una mujer la que amadrina un nacimiento ritualizado y una suerte de teremonia de baño, respectivamente. Sin embargo, estas variaciones son el resultado de las estructuras políticas y económicas de las sociedades que practican estos rituales. Los poderes creativos investidos en la comunidad y sus representantes son siempre medios de legitimar diferentes estructuras de dominación, sean de clase o género.

Así, en vez de tener variadas explicaciones para formas específicas, confrontamos un único acercamiento, que en contraste con Gudeman, no está inserto exclusivamente en la gran tradición. El punto de partida para la comparación cross-cultural es el complejo simbólico y sociológico del compadrazgo mismo.

Como puede apreciarse en el Cuadro 1 todas estas perspectivas pueden ser agrupadas esquemáticamente de acuerdo con su noción de variación y su visión del compadrazgo.

\section{COMPADRAZGO Y CUVADA}

Puede sugerirse que el ritual del bautismo conlleva dos funciones simbólicas principales que se encuentran separadamente en la cuvada y en los rituales de nombramiento ${ }^{6}$. Así, mientras el bautismo tiene a su cargo la creación del individuo eupiritual y la dación de un nombre - y la concomitante identidad social-, la cuvada sólo conlleva la primera función y los rituales de nombramiento, la última.

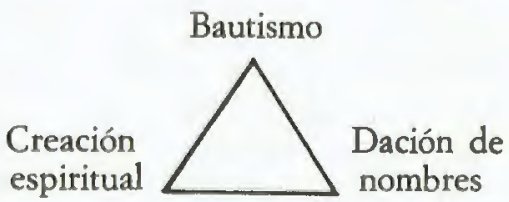

Cuvada $\leftrightarrow$ Rituales de Nombramiento

\section{Gráfico 3: La Cuvada y los Rituales de Nombramiento como} aspectos parciales del Bautismo.

Riviere (1974: 424) ha revelado que la definición de la cuvada es una gran trampa. Una de las razones para esta dificultad ha sido la diversidad de formas que esta exhibe - desde limitaciones en la dieta alimenticia hasta la simulación histrióni-

6 Para una comparación entre los rituales de nombramiento y el compadrazgo, véase Zarzar (1983a). 
ca del nacimiento por el padre. Otra razón, más profunda, es que la cuvada provee una manera de tratar con ideas metafísicas acerca del ser humano. Riviere concuerda con Kroeber en que la cuvada no es un fenómeno recurrente y definible, sino una variante de una serie de fenómenos interrelacionados. Pero también establece una distinción entre la cuvada como ritual y la cuvada como enfermedad psicosomática, para concentrarse en la primera, cuya definición básica es: "un conjunto de ideas y conductas convencionales que en esencia asocian a un bombre con el nacimiento de su hijo" (1974: 425, énfasis nuestro) ${ }^{7}$.

De acuerdo con Tylor y Frazer, la cuvada es una técnica de protección tanto . para el recién nacido como para los individuos relacionados con su nacimiento. Este raciocinio se soporta en la supuesta existencia de una conexión espiritual entre los padres y el niño. De acuerdo con Malinowski, la cuvada es una forma externa de los rituales de nacimiento, a la vez que un medio de reclamar la paternidad. De acuerdo con Van Gennep, esta es un rito de pasaje secundario, donde las restricciones en la dieta y la conducta ritual del hombre pueden ser un medio apropiado de simbolizar el periodo transitorio que es simultáneamente considerado peligroso y contaminante (en Riviere, ibid).

Pese a que estos aspectos funcionales y simbólicos al igual que estas explicaciones son parcialmente correctas, ellas no identifican la naturaleza del fenómeno, como tampoco se dirigen a su esencia. Siguiendo a Riviere, podemos intentar esa tarea mediante una comparación del compadrazgo con la cuvada usando sus ejemplos y otros más ${ }^{8}$. Entre los Waiwai y los Trio, ambas sociedades tribales del tronco lingüistico Caribe del Brasil y Guyana, las características principales y comunes de la cuvada son:

a) Esta implica restricciones tanto en la dieta como en las actividades de ambos padres, sin embargo no hay simulacro de dar a luz por parte del padre.

b) La duración e intensidad de la cuvada varía de acuerdo a la condición del niño. De ahí que no sea un ritual de pasaje, ya que la cuvada puede ser abandonada y nuevamente actualizada de acuerdo con las circunstancias.

c) Ambos grupos consideran que la sangre del nacimiento es contaminante.

Mientras que ambos grupos coinciden respecto a los aspectos prácticos de la cuvada, las creencias relativas a sus intenciones difieren levemente, Para los Waiwai, el objetivo de la cuvada es ayudar a fijar el alma aún débil del recién nacido; alma qué aún puede abandonar al niño, vagabundear y tornarse vulnerable ante cualquier peligro espiritual. Debido a la creencia en la existencia de un estrecho vínculo espiritual entre los padres y el niño, un peligro espiritual que actúe sobre los primeros afectará a este último. De ahí que la dieta y las actividades de los padres sufran restricciones.

De acuerdo con la cosmología de los Trio, en el nacimiento toda alma individual surge o se forma de un reservorio de almas y retorna a este con la muerte. En coincidencia con los Waiwai, los Trio creen que en el recién nacido esta alma no está ni adecuadamente fijada ni está suficientemente desarrollada como para que el niño

7 Enfasis que también se encuentra en los informes de Karsten (1926: 436-467) sobre la cuvada.

8 De acuerdo con Karsten, que ha recolectado una considerable cantidad de casos sobre cuvada y ha discutido algunas explicaciones sobre esta institución, esta no era exclusiva a la región amazónica pues informa de casos en las culturas andinas en el perfodo pre-colombino. 
uen un ser independiente. Esta alma crece a través de la alimentación espiritual de los padres efectuada mediante un cordón umbilical espiritual - contraparte del cordón Vulco- que continúa existiendo pasado el nacimiento.

En contraste con estos casos, entre los Urubu de la familia lingüistica Tupi la asociación mística entre los padres y el niño es en ambas direcciones. Se cree que si uno no cumple con seguir las restricciones prescritas pone en peligro su propia alma. Para los Urubu, la práctica de la cuvada es claramente un esfuerzo paterno de creación espiritual.

Otros casos de cuvada se encuentran entre los Krahó (Melatti 1979: 58) y los Apinayé (Da Matta 1979: 104). En ambas, sociedades Timbira del Brasil Central, las características de la cuvada mencionadas antes, se encuentran con variaciones que dependen de si las restricciones en la dieta, en las actividades o las relaciones sexuales comienzan antes o después del nacimiento del niño. Pero la creencia nuclear es la misma, los recién nacidos son seres incompletos hasta que sus almas son fijadas. Como en los otros casos, el nacimiento se considera una situación simbólicamente peligrosa.

En la cuvada reaparece la idea básica del bautismo como segundo nacimiento o nacimiento espiritual. Mientras que al dar a luz la mujer crea el cuerpo del niño, la cuvada es un segundo nacimiento que crea, transfiere o fija el alma al cuerpo del niño para hacer de él un ser humano completo. La imitación del parto practicada por el padre se explica y entiende como el parto de la naturaleza espiritual del niño. Tanto en la cuvada como en el compadrazgo estamos ante la idea que son necesarias dos acciones para darle existencia a un nuevo individuo. Sin embargo, mientras que en el compadrazgo estas acciones son realizadas por dos conjuntos distintos de padres, en la cuvada los padres naturales llevan a cabo tanto la creación natural como la espiritual. Riviere sugiere que esto es así porque en la cuvada "no hay unidades sociales identificables que sean equivalentes a la familia y al conjunto del compadrazgo" (1974: 432). Si bien es cierto que en la cuvada no hay unidades sociales identificables más allá y por encima de la familia, también es cierto que la creación espiritual es básicamente una función del rol del padre. La división que crea unidades sociales no se establece entre los progenitores y los otros miembros de la comunidad, pero sí entre los propios progenitores. El nacimiento está asociado no sólo con las mujeres y la creación física sino que también es considerado contaminante ${ }^{9}$ : más aún, este es asociado con la enfermedad ya que las mismas restricciones en la dieta y la conducta son aplicadas en ambas circunstancias. En los ejemplos anteriores, así como entre los Piro, el nacimiento es implícitamente considerado como un evento anormal, una enfermedad perturbadora que requiere control a través de la conducta ritual del padre. Nuevamente la oposición de géneros, señalada por Bloch y Guggenheim en el compadrazgo, reaparece en la cuvada. Este contraste puede expresarse en las siguientes analogías:

1) Nacimiento: Bautismo: Natural: Espiritual: Padres Naturales: Padres Espirituales.

2) Nacimiento: Cuvada: Natural: Espiritual: Madre: Padre.

La cuvada implica también una oposición entre los individuos que participan en el nacimiento y la esfera externa de las relaciones sociales. De acuerdo con Da Matta

9 Para más descripciones sobre este aspecto, véase Karsten (1926: 436-467). 
(1979: 105), las precauciones alimenticias crean una continuidad entre los progenitores y el recién nacido a la vez revelan una identificación basada en una esencia común compartida por ambas partes. Así, mediante el reforzamiento de sus vínculos biológicos comunes la 'familia nuclear' es contrastada con la esfera pública de las relaciones ceremoniales.

Para Riviere, la diferencia esencial entre el compadrazgo y la cuvada resulta del uso que hacen estas instituciones de diferentes modelos. En el compadrazgo, el modelo social es la 'familia' y las relaciones al interior de ella. En la cuvada, parte o todo el proceso de embarazo, parto y nutrición sirven como modelo físiológico para la creación espiritual. Sin embargo, estas diferencias no cancelan la posibilidad que una misma sociedad tenga ambas instituciones, como veremos en el caso de los Piro. Esto es importante pues puede significar, como ha notado Riviere (1974: 433-4), que la diferencia esencial entre el compadrazgo y la cuvada podría darse a un nivel institucional en casos específicos en vez de ser una característica universal.

\section{NACIMIENTO Y COMPADRAZGO: EL CASO DE LOS PIRO}

En contraste con otras sociedades, en las que el nacimiento es visto simplemente como un acontecimiento natural, aún cuando pueda ser considerado peligroso y contaminante, entre los Piro el nacimiento es un evento ritual. ${ }^{10}$ Este caso, junto con las prácticas de la cuvada, nos proveen de ejemplos que contradicen la idea de Gudeman (1972: 57) que el compadrazgo en tanto que marcado ritualmente se opone al nacimiento, evento no marcado ritualmente. Aún más y en respuesta a Riviere (1974: 433), el nacimiento entre los Piro, constituye un caso en el que la cuvada y el 'compadrazgo', instituciones usualmente separadas, son realizadas de manera complementaria.

Durante el ciclo vital de un Piro se crean lazos de padrinazgo en el nacimiento, el bautismo, la pubertad, la confirmación y el matrimonio. Sin embargo, estas ceremonias pueden reducirse a los tipos básicos del nacimiento y el bautismo de los cuales las otras son meras réplicas. Se puede decir propiamente que las instituciones nativas son usadas sólo en el nacimiento y la pubertad. Los otros rituales son cristianos.

Los Piro son un grupo etno-lingüistico Arawak que comparte una historia común, una cultura y un territorio básico, ${ }^{11}$ aunque en la actualidad carecen de una organización política centralizada y propia. Sin embargo, parece ser que tradicionalmente estuvieron organizados políticamente en clanes territoriales exogámicos dirigidos por líderes a nivel de asentamientos y regiones (Zarzar 1983: 35, 41). Esta estructura empezó a cambiar bajo el intenso aún cuando discontínuo proceso de colonización y terminó por derrumbarse en los inicios de este siglo bajo el impacto de la explotación cauchera. Hoy en día ya no puede decirse que los Piro constituyen una organización tribal. Aproximadamente 3,500 habitan las orillas del río Bajo Urubam-

10 De esto no se sigue que no existan otras sociedades en las que el nacimiento es un evento ritualizado. En este caso estamos no solamente ante rituales que imitan el nacimiento (como la cuvada) sino ante el hecho que el nacimiento mismo es ritualizado.

11 Como resultado del período de extracción cauchera, los Piro, al igual que un gran número de otros grupos, ocupan en la actualidad territorios alejados entre sí y hasta en diferentes cuencas. 
ba y parcialmente el Alto Ucayali, formando asentamientos exógamos dispersos y pequeñas comunidades. ${ }^{12}$ Estos ríos forman los canales de comunicación más grandes e importantes en el sureste de la Amazonía Peruana. Ubicación crucial que ha permitido a los Piro actuar como mediadores entre los diferentes sectores que han penetrado la región - misioneros, caucheros, comerciantes, madereros y en la actualidad compañias petroletas - y las otras, más pequeñas sociedades nativas de lós ríos tributarios.

Como pobladores ribereños, las actividades cotidianas y tradicionales de los Piro son principalmente la pesca y la agricultura de roce y quema, siendo la caza más bien esporádica. En la actualidad los Piro combinan estas actividades con trabajo asalariado temporal en la extracción de madera y con la venta de productos del monte a los mestizos.

La unidad básica de producción y consumo es la casa familiar usualmente compuesta por la familia nuclear. Las casas están ligadas a través de los cuñados y un sistema de matrimonio de primos cruzados; ambos vínculos proveen de cooperación en la agricultura y son utilizados para prestarse medios de producción. La distribución de la comida también involucra diferentes casas. Un Piro que ha obtenido una buena pesca o presa de caza, distribuirá su producto entre los miembros de su familia nuclear, la casa de sus padres y la de los padres de su esposa. Los lazos creados por el compadrazgo cristiano y el padrinazgo indígena también vinculan estas unidades sociales a través del intercambio de servicios, favores y bienes. En este sentido estas instituciones repiten las funciones del parentesco. La residencia es matrilocal y neolocal y la descendencia ha sido tradicionalmente matrilineal. Con la adopción de las costumbres occidentales y cristianas, como el compadrazgo, el matrimonio eclesiástico y el uso de apellidos con énfasis en el lado patrilateral de la familia, la regla de descendencia ha empezado a perder definición en favor de un sistema de parentesco bilateral.

\section{a) El Ritual del Nacimiento}

Para los Piro el nacimiento es un evento ritual. En vez de una ceremonia que imita el nacimiento, ${ }^{13}$ este deviene en un doble evento. $\mathrm{Al}$ momento del nacimiento, el padrino, que ha sido seleccionado con gran anticipación, corta el cordón umbilical. A través de esta acción, el padrino es asociado simbólicamente con la madre y el recién nacido. Al mismo tiempo, él o ella realizan la separación física del niño. Este acto de separar es un acto creativo. Sólo cuando la 'unidad' madre-hijo ha sido convertida en dos unidades, puede decirse que el niño ha empezado a existir como un individuo. Cabría preguntarse, ¿por qué alguien, fuera del padre o de la madre, tiene que intervenir? La respuesta se encuentra en las sugerencias hechas por Bloch y Guggenheim. Como en otros contextos culturales, entre los Piro, las mujeres no son consideradas capaces de producir seres sociales completos. ${ }^{14} \mathrm{La}$ intervención del pa-

12 Una excepción a este patrón es el poblado-frontera de Sepahua con más de 400 Piro junto con otros grupos y población mestiza.

13 Bloch y Guggenheim (1980) describen un ritual de nacimiento similar entre los Esquimales.

14 Una versión más sofisticada de esta oposición de géneros, en relación con la creación del cuerpo y el alma, puede encontrarse en la etnografía de Christine Hugh-Jones (1979: 125-135) sobre los indígenas Pira-Paraná en el noroeste de la Amazonía. 
drino expresa los poderes creativos y simbólicos asignados a la comunidad que aquél representa. Es la comunidad la que completa el niño y produce individuos socialmente aceptables.

Durante la ceremonia, los Piro designan al padrino con el término kpashiru (o), literalmente 'puro, intocable'. Estas características, contenidas en el significado del término, expresan el estatus superior del padrino, que se piensa adquiere tales virtudes por el contacto con la sangre de la madre, considerada sacralmente contaminante.

En la vida cotidiana el padrino es llamado nustakjeru, literalmente 'el que cortó el cordón'. Es interesante este contraste en los términos utilizados para designar al padrino pues si bien por un lado expresan la función práctica de éste, por otro lado establecen una marcada distinción entre el ámbito ritual y la vida secular. Los padres del apadrinado y el padrino se dirigen unos a otros con el término gistakjeru. El padrino se dirige a su ahijado con el término nustaplole. En la actualidad, los Piro al igual que otros grupos ribereños, también usan los diminutivos en castellano para compadre/comadre: 'cumpa' o 'cuma' y padrino/ahijado, reconociendo así las similitudes existentes entre el compadrazgo y su propia institución. Los términos tienen la siguiente equivalencia:

nustakjeru..... padrino

nustaplole..... ahijado

gistakjeru..... compadre

La institución nativa se halla inscrita en el sistema de parentesco pues los padrinos son preferencialmente y casi siempre elegidos de entre el grupo de parientes primarios (Alvarez, 1976). En este sentido, esta institución tiene una función intensificatoria, función que fuera señalada por Paul (1942) para el compadrazgo. Más aún, como en el compadrazgo, el conjunto de relaciones que esta institución establece no solamente está compuesto en su forma básica de los mismos miembros, sino que la naturaleza de las relaciones en también semejante. Un vínculo de parentesco liga a los padres con el niño mientras que un lazo espiritual liga al padrino con los padrés y con el niño. Sin embargo, los padres y el niño también están vinculados al padrino por lazos de parentesco.
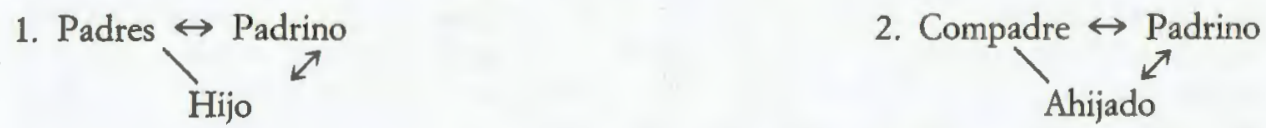

3. Gistakjeru $\leftrightarrow$ Nustakjeru

Gráfico 4. Conjunto de Relaciones en el Compadrazgo y la Institución de los Piro (donde 2 y 3 son repeticiones de 1.)

Como en el compadrazgo (Gudeman 1972: 62-63), los lazos espirituales creados por la institución nativa son repetidos mediante la incorporación de otros parientes. Así, el lazo de compadrazgo (gistakjeru) incluye a los hermanos de los padres. Los hermanos del apadrinado están relacionados con su padrino, y el niño (nusiaplole) 
considera como nustakjeru al padrino de sus hermanos. Sin embargo, estos son lazos secundarios que pueden definirse como relaciones de amistad formales.

En contraste con el compadrazgo, los Piro solamente seleccionan padrinos de entre los individuos de su red de parentesco. ${ }^{15}$ En orden decreciente los padres eligen como padrinos: a) los abuelos matrilaterales de ego $(1,2)$; b) los hermanos de la madre de ego $(3,4)$; c) los abuelos patrilaterales de ego $(5,6)$ y d) los hermanos del padre de ego $(7,8)$.

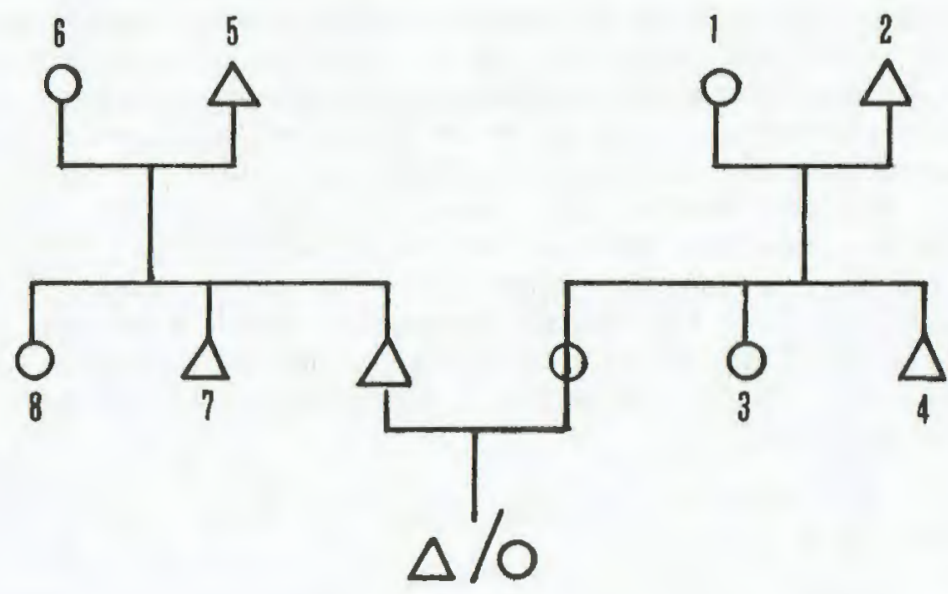

Ego

\section{Gráfico 5. Parientes elegidos como padrinos en el Ritual del Nacimiento Piro}

Como puede apreciarse, el lado matrilateral y la generación alterna de ego son los conjuntos preferidos de parientes. Esta manera de elegir es congruente con la regla tradicional de descendencia matrilineal y con el hecho que las personas mayores son más sabias y tienen más prestigio social. El rol del padrino - que entre otras funciones implica una guía espiritual y cultural- no sólo otorga prestigio al individuo elegido sino que requiere de personas prestigiadas y experimentadas.

Después del nacimiento, los padres practican la cuvada en su forma más común; se someten a las mismas restricciones en la dieta, las actividades productivas y las relaciones sexuales que han sido descritas para otras sociedades amazónicas. En contraste con esos casos, el padrino Piro participa de las mismas restricciones. Puede decirse en este respecto que la cuvada es un apéndice ritual que acompaña al evento ritualizado del nacimiento. Esta combinación produce una extraña mixtura del sim-

15 Una excepción que confirma esta regla fue mi designación y la de mi compañero de campo como padrinos de nacimiento, ambos ocupantes de un estatus no definido por el contexto social local. 
bolismo latente del compadrazgo y la cuvada. En el nacimiento como en el compadrazgo, el padrino es el encargado de la creación espiritual y social del niño. Después del nacimiento, y en oposición al bautismo, en la práctica de la cuvada se cree que los padres y principalmente el padre son los creadores del lado espiritual del niño, pero el padrino es incluído en las mismas restricciones.

En el nacimiento el padrino realiza la creación social del niño mientras que la creación espiritual, que se hace manifiesta después del nacimiento, es obra de los padres. Esta distinción puede ilustrarse con la ceremonia que sigue al nacimiento, en la cual el niño es presentado a la sociedad. La ceremonia se llama ishpa, literalmente orina en castellano. Los Piro dicen que ellos 'toman la ishpa del niño', cuestión que se realiza simbólicamente con la toma de masato (fermentado de yuca) a la salud del niño. En esta ceremonia, el rol del padrino adquiere plena relevancia respecto a la personalidad social del niño pues es el encargado de presentarlo ante la comunidad. ${ }^{16}$ Como fuera notado por Riviere (1974: 433) entre los Urubu: "es deber de los padres velar porque el niño sea un ser físico y espiritualmente completo, pero también hay un padrino... cuya tarea es presentar al individuo ya completado ante la comunidad... hay una distinción entre la persona física, espiritual y social". Así, mientras que el compadrazgo tiene que ver con el lado espiritual y con la identidad social del individuo, el ritual de nacimiento Piro y el padrino están asociados principalmente con esta última y la creación espiritual es llevada a cabo por los padres mediante la cuvada. Entre las dos instituciones Piro hay una relación de complementaridad y no una oposición; entre ambas, el padrino juega un rol mediador gracias a su doble participación. ${ }^{17}$

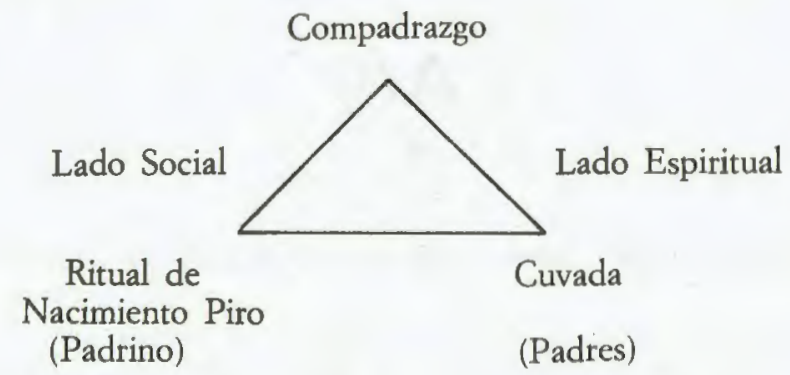

Gráfico 6. Padrinazgo y Cuvada entre los Piro.

El padrinazgo Piro está más cerca del compadrazgo que de la cuvada no solamente por las similitudes en sus fundamentos simbólicos, en los conjuntos de relaciones sociales y en las funciones del padrino, sino también porque ambas instituciones comparten las mismas normas y sus participantes se conducen socialmente de manera semejante. La prohibición del incesto entre los roles generados por el compadrazgo afecta también las relaciones entre los gistakjeru (padrino-padres) y entre el nustakje$r u$ y el nustaplole (padrino-ahijado). Las actitudes de respeto que marcan la conducta

16 Karsten (1926: 460) informa de una ceremonia similar entre los Jíbaro de la Amazonía Ecuatoriana.

17 Por haber sido elegido padrino de nacimiento se me prohibió comer sal y ají. 
entre los miembros del complejo del compadrazgo, también se encuentra en la instiIución nativa. Los padres y el ahijado no pueden dirigirse ante el padrino usando su nombre personal, ni pueden bromear con él. Cuando se encuentran con él no lo pueden mirar a la cara y las mujeres se cubren el rostro. Incluso la conversación con el padrino se lleva a cabo usando una voz impostada o falsete (Alvarez, 1976).

Las instituciones difieren en los criterios usados para elegir a los padrinos, Mientras que en el compadrazgo cristiano un criterio importante es el estatus socioeconómico del padrino, en la institución nativa este criterio no cuenta. Sin embargo, en ambos casos se espera ayuda mutua e intercambio de bienes, tanto entre los compadres como entre el padrino y el niño. Entre los Piro, los gistakjeru se ceden parcelas y pueden hacer un uso recíproco de sus cultivos. Nunca se roban entre ellos y por el contrario hasta se prestan dinero.

Como se puede apreciar, ambas instituciones se asemejan en las variadas dimensiones de sus fundamentos simbólicos y sus aspectos sociológicos. Sin embargo, el compadrazgo cristiano entre los Piro difiere en la práctica de la institución nativa del padrinazgo.

\section{b) El Compadrazgo Cristiano}

A pesar de la temprana presencia misional en la región habitada por los Piro, iniciada a mediados del siglo XVII, puede decirse que la institucionalización del compadrazgo cristiano no se desarrolló hasta pasado el periodo de la explotación cauchera. Antes de este boom económico la región estaba habitada principalmente por población nativa y unos pocos y dispersos comerciantes, colonos y misioneros católicos. Hacia fines del siglo pasado la región fue literalmente invadida por miles de hombres en busca del valioso caucho. Es entonces cuando se inician relaciones intensas y en gran escala entre las sociedades nativas y los afuerinos; relaciones en las cuales el compadrazgo jugó un papel crucial en tanto medio de legitimación de la dominación social y la explotación económica y como canal para el enganche o adquisición de la fuerza de trabajo indígena. Pero la frontera del caucho era itinerante. Al final de este período, hacia 1920, el sistema de haciendas establece una frontera sedentaria hasta 1950, en la que el compadrazgo se institucionaliza con las características de una relación de patronaje y clientelaje.

En la actualidad, la práctica del compadrazgo por los Piro los vincula con otros grupos 'tribales' y con la población mestiza. El 'poblado-frontera' de Sepahua, caracterizado por el cambio social y la interacción multiétnica provee el contexto para un examen comparativo de las diversas formas que adquieren los vínculos por compadrazgo.

Sepahua está habitada por los Piro (50\%), los Amahuaca (17\%) y los Yaminahua $(6 \%)$, que juntos representan el $73 \%$ de la población. El resto está compuesto por $16 \%$ de mestizos más $9 \%$ de estudiantes nativos de diferentes grupos étnicos del valle del Urubamba (los misioneros tienen un colegio internado) y algunos pocos individuos y familias de otros grupos étnicos $(2 \%)$. El total de la población es aproximadamente 900 . Sepahua puede caracterizarse gruesamente como un poblado estratificado en el que los mestizos ocupan la cúspide de la escala y los Yaminahua la base y entre ambos, los Piro y los Amahuaca. Mientras que las relaciones entre los grupos nativos y la población mestiza se caracterizan por la explotación económica y 
la dominación social, las relaciones entre los grupos nativos tienden a ser más igualitarias. La actual extracción maderera y el comercio —en el que los productos del bosque y del río son intercambiados por productos manufacturados- son las principales esferas de interacción entre nativos como trabajadores jornaleros y los mestizos como patrones y comerciantes. En este contexto, el compadrazgo conlleva dos conjuntos diferentes de vínculos: a) lazos de parentesco espiritual simétricos o 'intertribales' y b) lazos de parentesco espiritual asimétricos o interétnicos. Como han señalado Mintz y Wolf (1968: 352) el compadrazgo se encuentra comúnmente en contextos donde el cambio social ha alcanzado cierta estabilidad y en el que las relaciones entre estratos socio-culturales o clases se han consolidado.

Los lazos simétricos generados por el compadrazgo, junto con el matrimonio intertribal, son los canales principales para la cooperación en el trabajo, la reciprocidad en el intercambio de bienes y la ayuda mutua más allá de las fronteras étnicas. Sin embargo, los lazos por compadrazgo son opuestos a las alianzas matrimoniales al menos en un sentido: la prohibición del incesto cancela la posibilidad de matrimonio entre aquellos individuos involucrados en relaciones de compadrazgo. En Sepahua, el número de lazos de parentesco espiritual entre los Piro y los otros grupos nativos sobrepasa a los existentes entre los Piro y los mestizos. En un período de tres años, entre 1976 y 1978, de 95 niños Piro bautizados, 71 fueron apadrinados por padrinos nativos. En el caso del matrimonio intertribal, en 1977 entre 70 familias Piro, 23 estaban conformadas por parejas en las que uno de los miembros pertenecía a otro grupo nativo, mientras que 10 parejas estaban formadas con un miembro mestizo (Zarzar 1980).

Entre los Piro, el compadrazgo parece tener varios fines utilitarios. A través del bautismo ellos adquieren una identidad no indígena que les sirve como un pasaporte para el mundo de fuera de los mestizos. Como señala Osborn (1968: 598) para la Amazonia Colombiana "Un nombre cristiano.. es un "alma" o identidad en el mundo de fuera y un rótulo que ellos (los Kwaiker) emplean en sus contactos con el mundo externo y mediante el cual ese mundo los identifica'.

El compadrazgo vertical puede ilustrar ese hecho. Como fuera señalado antes, este es usado principalmente como una institución de patronaje o clientelaje en la que los mestizos o patrones intentan asegurar, a través de las obligaciones mutuas implicadas en los lazos de parentesco espiritual, la adquisición de fuerza de trabajo y recursos del bosque en un contexto donde el mercado de trabajo y de bienes es reducido y donde los nativos han logrado retener sus principales medios de producción y el acceso a los recursos naturales.

Por parte de los Piro, los lazos entre los compadres son una especie de seguro social, un canal más confiable para adquirir mercancías escasas como medicinas, ropa y dinero. La obligación económica del padrino hacia su ahijado y hacia sus compadres, que se expresa mejor en términos de una mayor generosidad, provee esta expectativa. Pero la distribución de la riqueza a través de los lazos de parentesco ritual es tan limitada que difícilmente puede cambiar las desigualdades prevalecientes. Al realizar transacciones económicas con un compadre mestizo, el Piro espera que esta se lleve a cabo con menos posibilidades de abuso. A través del compadrazgo, el Piro intenta obtener prestigio gracias a su vinculación espiritual con los individuos más poderosos del poblado. El compadrazgo también es un medio que les permite a los Piro interactuar en términos más igualitarios en sus encuentros 'cara a cara' con sus 
propios patrones. A pesar de esto, toda amistad entre Piros y mestizos es instrumental y sólo funciona a través del compadrazgo y las relaciones de patronaje y clientelaje.

La base socio-económica real y los valores étnicos que penetran estas relaciones impiden a los Piro devenir socialmente aceptables en el grupo de los mestizos: ellos permanecen como clientes o peones de los mestizos ${ }^{18}$ Como señala Chevalier (1982: 328) el compadrazgo puede servir para mantener "el sistema de explotación prevale" ciente gracias a la intervención de consideraciones domésticas en las relaciones materiales" que tiene como corolario la reducción del conflicto social local. Socialmente, el compadrazgo sólo se adapta a las condiciones existentes sin cambiarlas. Sin embargo, puede decirse que un efecto positivo e importante de los lazos por compadrazgo es la prohibición de matrimonio que estos conllevan, que contribuye al mantenimiento de la endogamia 'tribal' y étnica.

Finalmente es relevante mencionar una clara diferencia entre la institución del padrinazgo Piro y el compadrazgo. En una encuesta realizada entre 180 niños Piro, el $96 \%$ supo el nombre de la persona que cortó su cordón umbilical y aquel de sus hermanos, mientras que sólo el $16 \%$ recordó el nombre de sus padrinos de bautismo (Alvarez 1976). Esto nos indica no solamente que la institución cristiana tiene una importancia subordinada al ritual indígena sino también, que en la institución nativa el vínculo entre el padrino y el ahijado es altamente relevante, mientras que en los lazos cristianos el vínculo entre adultos y niños está subordinado a las relaciones entre los compadres.

\section{B I B L I O G R A F I A}

ALVAREZ, Ricardo O.P. 1976. "El Compadrazgo en una Tribu de la Amazonía Peruana" en Cuadernos de Realidades Sociales № 11. Instituto de Sociología Aplicada de Madrid.

BLOCH, Maurice and S. Guggenheim 1980. "Compadrazgo, Baptism and the Symbolism of a Second Birth" en Man 16, 376-86.

CHEVALIER, M. Jacques 1982. Civilization and the Stolen Gift: Capital, Kin and Cult in Eastern Peru. Universidad de Toronto, Canadá.

DA MATTA, Roberto 1979. "The Apinayé Relationship System: Terminology and Ideology" en Dialectical Societies. Maybury-Lewis, D (ed.)
EISTENSTADT, S.N. 1956. "Ritualized Personal Relations: Blood Brotherhood, Best Friends, Compadres, etc. Some Comparative Hypothesis and Suggestions" en Man 90.5

FOSTER, George M. 1953 "Cofradía and Compadrazgo in Spain and Spanish America" South Western Journal of Anthropology 9: 1-28.

GOODY, Esther N. 1971 "Forms of ProParenthood: The Sharing and Substitution of Parental Roles" en Kinship, Goody J. (ed.) Penguin.

GUDEMAN, Stephen 1972 "The Compadrazgo as a Reflection of the Natural and Spiritual Person" Proceedings of the Royal Anthropological Institute 45.71.

18 Una excepción a esta situación son las pocas familias mixtas Piro-Mestizo, compuestas sin embargo exclusivamente por trabajadores mestizos y no por patrones. 
GUDEMAN, Stephen 1975 "Spiritual Relationships and Selecting a Godparent" en Man 10: 221-37.

HUGH-JONES, Christine 1979 From the Milk River, Cambridge University Press.

KARSTEN, Rafael 1926 The Civilization of the South American Indians, Londres.

LEACH, Edmund 1969 Genesis as Myth and Other Essays, Ediciones Cape, Londres.

MAYBURY-LEWIS, David 1979 "Introduction" en Dialectical Societies. The Ge and Bororo of Central Brazil. Universidad de Harvard.

LEVI-STRAUSS, Claude 1943 "The Social Use of Kinship Terms among Brazilian Indians", reimpreso en Bohannan y Middleton (ed.) Marriage, Family and Residence, 1968.

MELATTI, Julio Cesar 1979. "The Relationship System of the Kraho" en Dialectical Societies. Maybury-Lewis (ed.)

MINTZ, S. Ward y E.R. Wolf 1968 "An Analysis of Ritual Co-Parenthood (Compadrazgo)" en Bohannan y Middleton (eds.) Marriage, Family and Residence, Nueva York.

NUTINI Y BELT 1980. Ritual Kinship: The Structure and Historical Development of the Compadrazgo System in Rural Tlazcala, Princeton University Press.

ORTNER, S. 1974 "Is Female to Male as Nature is to Culture?" en Woman,
Culture and Society, Lamphere, $M$ y M.Z. Rosaldo (eds.), Stanford University Press.

OSBORN, A. 1968 "Compadrazgo and $\mathrm{Pa}$ tronage: a Colombian Case" en Man 3 593-608.

PAUL, B.D. 1942 Ritual Kinship: with special reference to Godparenthood in Middle America, Tesis Doctoral (Ph.D) Universidad de Chicago.

PITT-RIVERS, Julian 1968 "Pseudo Kinship" en la International Encyclopedia of Social Science.

PITT-RIVERS, Julian 1977 The Fate of Schechem or the Politics of Sex. Es. says in the Anthropology of the Mediterranean. Cambridge Press.

REDFIELD, Robert y A. Villa Rojas 1962 Chan Kom: a Maya Village. Chicago y Londres.

RIVIERE, Peter C. 1974 "The Couvade: a Problem Reborn" en Man vol 9, No 3.

ZARZAR, Alonso 1980. "Fronteras de Penetración y Consecuencias en las Etnias del Bajo Urubamba" en Shupihui N 16, Iquitos, Perú.

ZARZAR, Alonso 1983. "Intercambio con el Enemigo; Etnohistoria de las Relaciones Intertribales en el Bajo Urubamba y Alto Ucayali" en Documento No 5, CIPA, Lima.

ZARZAR, Alonso 1983a. The Variations of the Compadrazgo Complex: Contribution to a Discussion. Tesis de Master (M. Phil), Universidad de Cambridge. 